\title{
LA CAPACITACIÓN COMO MOTOR DE IMPULSO PARA EMPRENDEDORES CON UNA PROPUESTA POR COMPETENCIAS: EXPERIENCIA PRÁCTICA CON UN GRUPO DE MUJERES DE LA COMUNIDAD DE NARANJO, COSTA RICA
}

\author{
ANIA BLACKWOOD MC LEAN \\ Universidad Estatal a Distancia, Costa Rica \\ ablackwood15@gmail.com
}

\section{RESUMEN}

El Programa de Desarrollo Gerencial (PDG) de la Dirección de Extensión de la Universidad Estatal a Distancia (UNED) logra mediante sus diversos servicios de capacitación ofrecidos a instituciones estatales o empresas privadas, desarrollar un programa de capacitación para mujeres empresarias a través de la Oficina de la Mujer del cantón de Naranjo en la Provincia de Alajuela, Costa Rica. El artículo presenta desde el punto de vista de la autora los pasos clave para desarrollar una capacitación basada en competencias específica para este sector productivo, con el fin de facilitar una guía de referencia cuando se conducen sesiones de capacitación similares.

PALABRAS CLAVES: EMPRENDIMIENTO, COMPETENCIAS, CAPACITACIÓN, INNOVACIÓN, PLANEACIÓN DE NEGOCIOS.

\section{ABSTRACT}

The Management Development Program (MDP) of the Extension Department of the Costa Rican University of Distance Education (UNED), through its various training services offered to public entities or private companies, has developed a training program for women entrepreneurs together with the Women's Office of the community of Naranjo in the Province of Alajuela, Costa Rica. This article presents the key steps to develop a competency-based training program particularly for this productive sector in order to offer it as a reference guide when conducting similar training endeavors.

KEYWORDS: ENTREPRENEURSHIP, COMPETENCES, TRAINNIG, INNOVATION, BUSINESS PLANNING.

\section{INTRODUCCIÓN}

La corriente globalizadora así como la crisis económica y financiera mundial del 2008, instauraron una serie de medidas precautorias en cuanto al empleo y la productividad, y han moldeado el esquema tradicional de trabajo hacia diversos conceptos que han contribuido con el replanteamiento del perfil para abarcar los procesos productivos. La Oficina Subregional de la Organización Internacional del Trabajo señala en su informe "Impactos de la crisis mundial en el mercado laboral de Centroamérica y República Dominicana" (2009):

(...) debido a la prioridad que es el mantenimiento del trabajo, han optado por políticas para mantener los puestos de trabajo, el poder de compra, promover la generación 
de micro y pequeños emprendimientos, así como para quienes terminan desempleados, opciones para continuar su protección social y la reconversión de sus competencias laborales (p.6).

Es común escuchar sobre programas de capacitación para micro, pequeños y medianos empresarios, al lado de un fuerte impulso para proyectos innovadores que capten un espacio real y promisorio en el mercado, que se transforma debido a las contracciones económicas, que no sólo afectan de forma generalizada a todos los sectores productivos, pero sí afectan a sectores poblacionales particulares que históricamente han sido sublevados a otro tipo de actividades no consideradas como productivas, tal es la situación de algunas mujeres que no cuentan con un trabajo formal, son las encargadas unilateralmente de llevar el sustento económico a sus hogares gracias a la venta de productos y servicios, en algunos casos, otras tienen una idea innovadora pero no han sabido cómo hacer despegar su visión a fin de obtener un lugar dentro del mercado altamente competitivo.

Aunque los esfuerzos en cuanto a política pública por parte de los gobiernos siguen necesitando mayor empuje, ciertas organizaciones han volcado su interés en la figura del emprendedor o emprendedora que tiene su micro o pequeña empresa como forma de subsistencia. Dichas organizaciones son atraídas ante el espíritu emprendedor para crear negocios, se preocupan por la escasez de empleo formal e inclusive por motivos del nivel de educación en algunos casos.

Tal es el esfuerzo empleado por la Universidad Estatal a Distancia (UNED) a través de sus diversas instancias, y en el marco de este estudio en particular, a través del Programa de Desarrollo Gerencial de la Dirección de Extensión en asocio con sus aliadas instituciones privadas o la figura del emprendimiento se distingue de otras figuras empresariales en el sentido que por lo general es una única persona la que desarrolla su negocio gracias al empuje motivacional que la guía a lograr sus objetivos; en palabras de Mussons (1999) señala al respecto que "(...) un emprendedor es un creador y director de empresa con carácter innovador y orientado al crecimiento." (p.31). La persona innovadora y con sentimiento de lucha por lograr el crecimiento, es uno de los distintivos del emprendedor.

Alcaraz (2011) amplía aún más la definición de emprendedor incluyendo más características de la personalidad y del conocimiento que se vislumbra en mayor o menor medida en un emprendedor:

(...) el emprendedor es una persona que posee un alto grado de confianza en sí mismo y una serie de características que le permiten detectar oportunidades y generar conceptos de negocio a partir de la creación, la innovación o el mejor empleo de los recursos para alcanzar objetivos. En este contexto, asume el riesgo inherente a su toma de decisiones y persevera en la puesta en marcha de su proyecto (p. 8).

La experiencia de desarrollo de un taller de capacitación con emprendedoras de la comunidad de Naranjo, hace plantear la necesidad de sintetizar esas características que se buscaron fortalecer en las mujeres participantes por lo que en este estudio se pretende proponer una serie de pasos o aspectos a considerar para desarrollar eficazmente competencias en los emprendedores que si bien algunos presentarán las características de forma destacada, otros requerirán mayor entrenamiento. Así mismo lo constata González (2007) al afirmar que "si se está en esa etapa (de preparación antes de iniciar un proyecto), se puede aprovechar para fortalecer las áreas que están deficientes, capacitarse o iniciar con la planeación de esa gran idea" (p.5). 
Hablar de competencias es hablar de comportamientos inherentes a la personalidad y conocimiento que permiten que un individuo se desenvuelva destacadamente en una actividad o tarea por encima de otros. La palabra competencia llama la atención de observadores y expertos después de que Mc Clelland (1973) quien en su publicación "Testing for Competence rather than for Inteligence", hace una fuerte crítica hacia las pruebas de aptitud y el poder que tenían para decidir el futuro de los estudiantes universitarios o los candidatos a un puesto. El estudio consistió en hacer una comparación entre las personas que obtenían buenas calificaciones en paralelo con las personas que no obtuvieron tan buenas calificaciones, durante el periodo de estudio, se demostró que ambos lograban bueno estándares de vida laboral a futuro y se determinó además que las buenas calificaciones en el colegio no necesariamente eran sinónimo de otros comportamientos de éxito en la vida.

En palabras de los autores Spencer y Spencer una competencia es "una característica subyacente de un individuo que está casualmente relacionada a un criterio referenciado como efectivo y/o un desempeño superior en un trabajo o situación" (como se cita en Alles, 2008, p.26).

Finalmente, se pretende mostrar una retrospección de las competencias detectadas en las participantes de la capacitación. Además de evidenciar aquellas características de la personalidad deseadas en un emprendedor que lo hace sobresalir sobre otros en la ejecución de una tarea determinada; pero sobre todo mostrar la forma más efectiva de desarrollar determinadas competencias en sesiones de capacitación.

\section{METODOLOGÍA}

El estudio tiene una tendencia hacia el enfoque cualitativo, como indican Hernández, Fernández y Baptista, (2003) "se enfoca a comprender y profundizar los fenómenos, explorándolos desde la perspectiva de los participantes en un ambiente natural y en relación con el contexto" (p.364). El enfoque cualitativo se encarga de entender una situación social como un todo de forma general; dentro de la investigación se busca proponer a raíz de una experiencia de capacitación, sobre las mejores técnicas de capacitación para el desarrollo de emprendedores, dada la relevancia que ha ido adquiriendo el tema. Además de buscar mayores espacios de discusión en torno a dinámica de aprendizaje que se debe manejar con los emprendedores.

El alcance de la investigación se enmarca dentro de los estudios exploratorio- descriptivos, por un lado porque involucra aquellos estudios que han sido poco explorados y por el otro describen una situación particular. Según Hernández et. al. (2010) mencionan que "Los estudios exploratorios se efectúa normalmente cuando el objetivo es examinar un tema o problema de investigación poco estudiado y del cual se tienen muchas dudas o no se ha abordado antes". (p.79).

La investigación se caracteriza como descriptiva, debido a que detalla las vivencias dentro de la capacitación como herramienta para sustentar el planteamiento. Hernández et. al. (2010) señalan que "los estudios descriptivos buscan especificar las propiedades, las características y los perfiles de personas, grupos, comunidades, procesos, objetos o cualquier otro fenómeno que se someta a un análisis." (p.80).

La población de interés corresponde a un grupo 30 mujeres que se inscribió en el curso para emprendedoras con enfoque en planeación de negocios dirigido por el Programa de Desarrollo Gerencial de la Dirección de Extensión de la UNED, en el cantón de Naranjo de la provincia de Alajuela, Costa Rica. 
TABLA 1

POBLACIÓN DE INTERÉS

\begin{tabular}{|l|c|}
\hline \multicolumn{1}{|c|}{ TIPO DE NEGOCIO } & $\begin{array}{c}\text { CANTIDAD DE } \\
\text { PARTICIPANTES }\end{array}$ \\
\hline Servicios de alimentación & 13 \\
\hline Manualidades & 5 \\
\hline Textil & 3 \\
\hline Bisutería & 3 \\
\hline Confección de bolsos & 2 \\
\hline Reciclaje & 2 \\
\hline Salón de Belleza & 1 \\
\hline Administración Guardería & 1 \\
\hline TOTAL & 30 \\
\hline
\end{tabular}

Fuente: elaboración propia.

La recolección de información que facilitó hacer este estudio, se efectuó mediante el desarrollo de talleres de capacitación durante un espacio de seis meses la primera etapa de diagnóstico, conocimiento y práctica durante el segundo semestre del año 2010. La segunda es una etapa de seguimiento llevada a cabo en el transcurso del primer trimestre del año 2011. Ambas etapas se desarrollaron en las instalaciones de la Municipalidad de Naranjo y sus alrededores.

La observación tuvo un papel de relevancia a la hora de examinar los comportamientos expresados por las participantes en torno a la asimilación de la información facilitada, así como el propicio de espacios para realimentación no solo de la vía de enseñanza profesor - estudiante, estudiante - profesor; sino también estudiante- estudiante, en el que la experiencia de una enriquece a la otra. Se realizó un cuestionario de diagnóstico para conocer la situación actual de las participantes en relación con sus proyectos emprendedores y un cuestionario final de evaluación del curso.
El método de calificación fue cualitativo por lo que se valoró la entrega oportuna de las asignaciones y la participación en las diversas sesiones.

\section{RESULTADOS Diagnóstico, conocimiento y práctica}

Bajo el nombre de Antología sobre capacitación en planes de negocios de Poveda, Parada, Vega, Araya, Acuña, Arguedas, Ferreto, Vidas, y Cheng, (2009) fue entregada a cada una de las participantes, y sirvió como material complementario para diagnosticar la situación actual de las ideas de negocio.

En la tabla 2 se aprecian las preguntas originalmente planteadas durante los talleres de capacitación y una propuesta de preguntas bajo el enfoque por competencias, se plantea en la columna contigua a manera de comparación.

En el conjunto de preguntas de diagnóstico, se han incorporado preguntas usando la técnica de selección por competencias, que consiste en indagar lo que realmente hace, es decir, la forma en que realmente se comporta ante determinada situación haciendo énfasis en la conducta pasada del individuo, de esa forma se espera tener un panorama más claro del nivel de competencia reflejada en la persona que contesta. Según Jiménez (2007) la definición de selección por competencias es la siguiente:

(...) es una técnica de exploración que obtiene información sobre comportamientos concretos (acciones, pensamientos y sentimientos) con el fin de analizar las competencias propias del candidato en relación del perfil del puesto que va a cubrir, para ello se recurre a la técnica de los incidentes críticos. (Hechos relativamente recientes, vividos por el candidato, sobre los que se proyecta su forma de pensar, sentir y actuar) (p.143). 


\section{TABLA 2}

\section{PREGUNTAS DE DIAGNÓSTICO}

\section{Preguntas originalmente planteadas}

\section{Ejemplo de preguntas bajo un enfoque por competencias}

\begin{abstract}
¿La nueva idea de negocio logra motivarla realmente?
\end{abstract}

¿Cuenta con los conocimientos técnicos para la elaboración del producto o la presentación del servicio?

Tiene apoyo de su familia?

¿Tiene entera confianza en sí misma?

¿Es su idea algo novedoso?

¿El negocio puede hacerse en forma diferente?

¿El producto o servicio resuelve el problema de los clientes?

¿El producto o servicio cumple un deseo de los clientes?

¿El producto o servicio satisface una necesidad de los clientes?
¿Recuerda cuál fue la razón por la que decidió tomar su idea de negocio? ¿Cuál fue su motivación?

Cuénteme: ¿cómo elabora su producto?¿Cómo brinda su servicio?

Trate de recordar algún momento en el que pidió ayuda de algún familiar o amistad, para realizar una tarea de su negocio pero la respuesta fue negativa. ¿Qué hizo usted ante esa respuesta? ¿Qué pasó al final?

En algún momento le sucedió que usted tenía una opinión de cómo resolver un problema con su producto pero otra persona le insistió en que usted estaba equivocada, aunque el fondo usted sabía que tenía la razón. ¿Qué hizo al respecto? ¿Qué le dijo usted a la otra persona?

Cuénteme de algún momento en que usted impresionó a un cliente con la entrega de su producto. ¿Qué fue lo que impresionó tanto a su cliente de su producto?

Se han acercado o recuerda haber visto a otras personas con su misma idea de negocios? ¿Cómo se sintió cuando supo de ellos?

Describa algún momento en el que tuvo que hacer un esfuerzo adicional para entregar a tiempo su productor a un cliente. ¿Qué sucedió al final?

Fuente: elaboración propia basada en Poveda et al. (2009).

Si bien la técnica de selección de personas se sitúa en el marco de una organización en la que se requieren empleados para ocupar un determinado puesto, esta investigación propone que la técnica se puede extrapolar al diagnóstico del grado de competencias mostradas por un emprendedor con el objetivo de conocer sus destrezas, conocimientos y habilidades en una forma más profunda y de allí extraer las competencias que mayormente tiene que desarrollar.
Para aplicar la técnica de hacer preguntas por competencias, éstas deberán plantearse en pasado de modo que sean un reflejo de una posible conducta futura. Alles (2010) se refiere al indicador para detectar comportamientos futuros de una persona al indicar que "(...) la manera en que un postulante ha enfrentado una situación específica pasada es la mejor indicación para verificar cómo se desempeñará en una situación similar en el futuro." (p.43). Por ejemplo, en lugar de 
preguntar: ¿es su negocio algo novedoso?, en el que la respuesta probablemente sea un sí, porqué mejor no indagar más haciendo preguntas identificando su comportamiento pasado ante una situación específica para determinar con exactitud si cuenta con las competencias necesarias para que su negocio salga a flote.

Una vez efectuado el diagnóstico y revisado con las participantes se recurrió al desarrollo de conocimientos técnicos en materia de gestión estratégica, mercadeo, organización, financiero-contable, tramitología entre otros, con el fin de cumplir con la didáctica planteada. El diseño curricular del curso contempló desde un inicio trabajar desde la parte emotiva, creativa y de equipo con las participantes, combinando el conocimiento con el impulso de habilidades específicas, como resultado de las expectativas expresadas por las participantes durante el proceso de diagnóstico. El objetivo era transmitir el conocimiento sobre la creación de un plan de negocios, pero las técnicas relacionadas a la personalidad y otras competencia del conocimiento que se desarrollaron, fueron gracias a las mismas peticiones de las participantes y de las inquietudes que fueron surgiendo a la largo del curso.

El desarrollo de competencias del conocimiento no debería basarse en un esquema rígido de enseñanza-aprendizaje para un sector de emprendimiento; una dinámica flexible que incorpore el ejercicio de las competencias deseadas en el grupo capacitado y que responda a las interrogantes particulares de cada una será clave en las sesiones. En la Tabla 3 se sintetiza las habilidades que se manejaron y tuvieron mayor presencia durante la capacitación.

TABLA 3

\section{DESARROLLO DE LAS COMPETENCIAS}

\begin{tabular}{|c|c|c|c|}
\hline $\begin{array}{l}\text { COMPE- } \\
\text { TENCIA }\end{array}$ & DEFINICIÓN & ACTIVIDAD & OBJETIVO \\
\hline $\begin{array}{l}\text { Confianza en } \\
\text { sí mismo }\end{array}$ & $\begin{array}{l}\text { "Es el convencimiento de que } \\
\text { uno es capaz de realizar con } \\
\text { éxito una tarea o elegir el enfo- } \\
\text { que adecuado para resolver un } \\
\text { problema". }\end{array}$ & $\begin{array}{l}\text { Charla motivacional: } \\
\text { "La luciérnaga y la } \\
\text { serpiente." } \\
\text { Dinámica: Técnica de } \\
\text { salida. Dinámica: Foto } \\
\text { proyección. }\end{array}$ & $\begin{array}{l}\text { Enfatizar la existencia de obstáculos y la } \\
\text { necesidad de afrontarlos con confianza. } \\
\text { Desarrollar el concepto de superar los te- } \\
\text { mores a través del análisis de los medios } \\
\text { que se están utilizando y la búsqueda de } \\
\text { nuevas salidas si el plan inicial no está } \\
\text { dando resultados. } \\
\text { Describir cómo cada persona se comporta } \\
\text { según su propia historia de vida. Reforzar la } \\
\text { reflexión apropiada para el encuentro con } \\
\text { uno mismo y sus temores para posterior- } \\
\text { mente afrontarlos. }\end{array}$ \\
\hline $\begin{array}{l}\text { Pensamiento } \\
\text { estratégico }\end{array}$ & $\begin{array}{l}\text { "Es la habilidad para compren- } \\
\text { der rápidamente los cambios } \\
\text { del entorno, las oportunidades } \\
\text { del mercado, las amenazas } \\
\text { competitivas y las fortalezas y } \\
\text { debilidades de su propia orga- } \\
\text { nización a la hora de identificar } \\
\text { la mejor respuesta estratégica. } \\
\text { Capacidad para detectar nuevas } \\
\text { oportunidades de negocios, } \\
\text { comprar negocios en marcha, } \\
\text { realizar alianzas estratégicas } \\
\text { con clientes, proveedores o } \\
\text { competidores. Incluye la capa- } \\
\text { cidad para saber cuándo hay } \\
\text { que abandonar un negocio o } \\
\text { remplazarlo por otro." }\end{array}$ & $\begin{array}{l}\text { Dinámica de presen- } \\
\text { tación. } \\
\text { Encuesta de mercado } \\
\text { para productos o ser- } \\
\text { vicios. }\end{array}$ & $\begin{array}{l}\text { Enfatizar la importancia de ir formando } \\
\text { lazos empresariales entre las personas con } \\
\text { negocios similares o intereses particulares. } \\
\text { Probar el conocimiento que cada una de } \\
\text { las participantes tiene sobre su negocio } \\
\text { en cuanto a la percepción de clientes y su } \\
\text { espacio en el mercado. }\end{array}$ \\
\hline
\end{tabular}




\begin{tabular}{|c|c|c|c|}
\hline $\begin{array}{l}\text { Trabajo en } \\
\text { equipo }\end{array}$ & $\begin{array}{l}\text { "Es la habilidad para participar } \\
\text { activamente de una meta co- } \\
\text { mún, incluso cuando la colabo- } \\
\text { ración conduce a una meta que } \\
\text { no está directamente relaciona- } \\
\text { da con el interés personal." }\end{array}$ & $\begin{array}{l}\text { Video: Cualquier video } \\
\text { que ilustre el trabajo en } \\
\text { equipo. } \\
\text { Ejercicio de equipo: La } \\
\text { Avenida complicada. } \\
\text { Feria de manualidades y } \\
\text { artesanía. }\end{array}$ & $\begin{array}{l}\text { Generar la necesidad de valorar los logros } \\
\text { de la aplicación del trabajo en equipo. } \\
\text { Desarrollar el pensamiento analítico junto } \\
\text { con la participación de un equipo para } \\
\text { Ilegar a consenso. } \\
\text { Capturar la esencia del trabajo en equipo } \\
\text { mediante el desarrollo de una feria de ma- } \\
\text { nualidades y artesanía. }\end{array}$ \\
\hline Iniciativa & $\begin{array}{l}\text { "Es la predisposición a actuar } \\
\text { proactivamente y a pensar no } \\
\text { sólo en lo que hay que hacer } \\
\text { en el futuro." Los niveles de } \\
\text { actuación van desde concretar } \\
\text { decisiones tomadas en el pasa- } \\
\text { do hasta la búsqueda de nuevas } \\
\text { oportunidades o soluciones a } \\
\text { problemas. }\end{array}$ & $\begin{array}{l}\text { Estudio de caso: El ne- } \\
\text { gocio de Doña Lolita. }\end{array}$ & $\begin{array}{l}\text { Generar la iniciativa en las participantes } \\
\text { para retomar proyectos pendientes o poner } \\
\text { en marcha ideas de negocio. }\end{array}$ \\
\hline $\begin{array}{l}\text { Comunica- } \\
\text { ción }\end{array}$ & $\begin{array}{l}\text { "Es la capacidad de escuchar, } \\
\text { hacer preguntas, expresar con- } \\
\text { ceptos e ideas en forma efectiva } \\
\text { y exponer aspectos positivos." } \\
\text { La habilidad de saber cuándo } \\
\text { y a quién preguntar para llevar } \\
\text { adelante un propósito. Es la } \\
\text { capacidad de escuchar al otro y } \\
\text { comprenderlo. Comprender la } \\
\text { dinámica de grupos y el diseño } \\
\text { efectivo de reuniones. Incluye } \\
\text { la capacidad de comunicar } \\
\text { por escrito con concisión y } \\
\text { claridad. }\end{array}$ & $\begin{array}{l}\text { Comunicación efectiva. } \\
\text { Comunicación no ver- } \\
\text { bal. }\end{array}$ & $\begin{array}{l}\text { Ahondar en las diversas interpretaciones } \\
\text { que pueden surgir a través de la comuni- } \\
\text { cación. Enfatizar los aspectos propios de la } \\
\text { comunicación efectiva, así como las carac- } \\
\text { terísticas de la asertividad. }\end{array}$ \\
\hline Negociación & $\begin{array}{l}\text { "Habilidad para crear un am- } \\
\text { biente propicio para la colabo- } \\
\text { ración y lograr compromisos } \\
\text { duraderos que fortalezcan la re- } \\
\text { lación." Capacidad para dirigir } \\
\text { o controlar una discusión uti- } \\
\text { lizando técnicas ganar - ganar } \\
\text { planificando alternativas para } \\
\text { negociar los mejores acuerdos. } \\
\text { Se centra en el problema y no } \\
\text { en la persona. }\end{array}$ & $\begin{array}{l}\text { Signos gestuales carac- } \\
\text { terísticos de un proceso } \\
\text { de negociación. } \\
\text { La proxemia en los pro- } \\
\text { cesos de negociación. } \\
\text { Elementos paralingüísti- } \\
\text { cos de la negociación. }\end{array}$ & $\begin{array}{l}\text { Mostrar las diversas técnicas de negocia- } \\
\text { ción reflejadas a través de la comunicación } \\
\text { no verbal }\end{array}$ \\
\hline Innovación & $\begin{array}{l}\text { "Es la capacidad de idear so- } \\
\text { luciones nuevas y diferentes } \\
\text { para resolver problemas o } \\
\text { situaciones requeridas por el } \\
\text { propio puesto, la organización, } \\
\text { los clientes o el segmento de al } \\
\text { economía donde actúe." }\end{array}$ & $\begin{array}{l}\text { Feria de novedades y } \\
\text { artesanía. } \\
\text { Desarrollo innovador } \\
\text { de cada una de las } \\
\text { sesiones. }\end{array}$ & $\begin{array}{l}\text { Demostrar a través de diversas técnicas que } \\
\text { las acciones se pueden hacer diferentes a } \\
\text { la forma en que tradicionalmente se reali- } \\
\text { zaban. }\end{array}$ \\
\hline
\end{tabular}

Fuente: elaboración propia con definiciones basadas en Alles (2007). 
El orden en que se desarrollen las competencias no debería ser trascendental, siempre y cuando se cuente claramente con habilidades requeridas. La cantidad de competencias a desarrollar dependerá del espacio de tiempo con que se cuente, debido a que se requiere suficiente tiempo para que la persona asimile la habilidad, la ponga en práctica y posteriormente interiorice lo aprendido para evaluar si realmente la está desarrollando. No existe problema alguno en combinar competencias relacionadas cuando se imparte una sesión. De hecho pueden existir competencias estrechamente relacionadas entre sí.

De forma general no se espera que el facilitador aplique las dinámicas aquí planteadas, las mismas pueden variar siempre y cuando se tenga claro cuál es el comportamiento que se analizará.

Es aconsejable en materia de competencia brindar el conocimiento, es decir, la teoría, pero que ésta se desarrolle luego de forma práctica, esto es por medio de un trabajo de campo en el que el participante realmente ponga de manifiesto todo el aprendizaje adquirido. Con base en esta temática Alles (2008) se refiere a las acciones para desarrollar competencias en una capacitación:

(...) un curso formal sobre la competencia a desarrollar. El entrenamiento derivado del propio desempeño en un puesto: los resultados de las evaluaciones, los comentarios diarios de los superiores y las indicaciones cotidianas en el trabajo sirven como retroalimentación para el desarrollo de competencias. El autodesarrollo es, sin embargo, la base de la generación de competencias (p. 58).

El enfoque que utiliza Alles es en torno a organizaciones y un puesto laboral. Sin embargo, en materia de emprendimiento donde en algunas ocasiones el jefe es el mismo empleado, se puede utilizar la misma dinámica en el que el facilitar propicia el curso forma, la transmisión de cono- cimiento a los participantes, se brinda realimentación a través de los comentarios del facilitador y participantes y por su puesto se pone en práctica lo aprendido.

Uno de los primeros ejercicios consistió en que a través de un análisis de su entorno conocido como Análisis de Fortalezas, Oportunidades, Debilidades y Amenazas (FODA) identificaran las suyas propias a sus negocios. Se utilizó la fábula conocida como "La luciérnaga y la serpiente", en el cual se compararon mediante una lluvia de ideas las fortalezas de la luciérnaga analógicamente como representación de sus propios negocios, versus la serpiente que en ese ejercicio representó las amenazas.

Se sugiere al facilitador de un curso de emprendimiento desarrollar la competencia de confianza en sí mismo debido a la necesidad de romper esquemas negativos de imposibilidad de cumplir con objetivos que podrían tener este tipo de poblaciones. González (2007) hace referencia a los esquemas apuntados clasificándolos en barreras económicas, psicológicas y culturales. Algunos emprendedores podrían pensar que no tener suficiente dinero podría ser obstáculo para ejercer con éxito su negocio o cuestiones propias del género donde creencias infundadas no permitan avanzar con una idea, e inclusive bloqueos mentales relacionados a experiencias pasadas podrían estar imposibilitando la concreción de un sueño.

Otro ejercicio que apoyó liberar algunos temores, timidez y darles mayor confianza en sus capacidades fue el ejercicio conocido como "técnica de salida" aplicado con base en Fritzen (1984). La técnica consiste en formar círculos de aproximadamente 12 personas cada uno, los participantes entrelazan sus brazos, seguidamente un participante debe entrar en el círculo formado y luego tratar de escaparse, pero el grupo tratará de bloquear a la persona evitando que salga por unos 5 minutos, luego intercambiar con otro participante. 
Para que el ejercicio tenga mayor impacto es preferible buscar a los participantes más vulnerables. Para este curso en específico, una de las participantes dijo haber sentido tranquilidad cuando logró salir del círculo. Todos los comentarios que surjan deben de aprovecharse al máximo para fortalecer el desarrollo de la competencia.

Ejecutar la técnica de la foto proyección hace que el participante exprese, sin saberlo, sus miedos más profundos y aspiraciones frustradas, por medio de la utilización de fotos recortadas de revistas en el que se aprecian personas y paisajes. Los participantes tienen que crear una historia sobre la fotografía. Esta técnica, aunque excelente para reforzar la confianza al hablar de problemas que aquejan a la persona, puesto que al final se está reflejando ella misma en la historia, debe ser manejada con profuso cuidado en un ambiente de respeto, aunque las participantes del curso expusieron sus resultados frente al resto del grupo, se recomienda hacerlo en una sesión a parte con el participante y el facilitador únicamente. Es tanta la información personal del participante que se llega a extraer de la técnica, que si no se maneja con cuidado puede desviar el objetivo de la capacitación.

Se inspiró el pensamiento estratégico por medio de la agrupación de proyectos de negocios similares, por ejemplo agrupar a la que se encargaba de la confección de bolsos con la diseñaba y confeccionaba prendas de vestir en donde intercambiaron información sobre novedosas y eficaces para etiquetar sus productos. Sobre ello, se enfatizó la importancia de formar alianzas de negocios entre ellas mismas para formar equipos sólidos y fuertes ante la competencia. En algún momento durante el curso se tuvo la presencia de una asociación que les brindó una charla sobre la importancia de unir esfuerzos para formar parte de un proyecto en el que todos podrían participar con el fin de centralizar sus proyectos para exponer y vender a los turistas que llegaban a la zona.
Retarles en que la idea de negocios que tenían no era, necesariamente, lo que necesitaba el cliente fue un tema que se analizó ampliamente, precisamente para crearles la inquietud de si una idea no es buena o un negocio no resulta hay que pensar estratégicamente para determinar la mejor salida, tener un panorama de posibles soluciones, ésta puede consistir en buscar otro negocio, aliarse con otro o diversificar el producto o servicio ya existente. Con relación a los riesgos que se encuentran en el mercado Alcaraz (2011) menciona:

Cualquier nueva empresa que entra en el mercado debe elaborar un listado de los posibles riesgos y oportunidades del lugar donde incursiona. Lo anterior le permitirá desarrollar eventuales planes de acción que faciliten la toma de decisiones en el momento en que se llegara a presentar cualquier contingencia (p.107).

Para la puesta en práctica de lo expuesto en las sesiones, se les pidió que hicieran una encuesta de mercado, previamente explicándoles su diseño e importancia, para determinar variables como el precio, percepción y conocimiento del producto por parte del encuestado, entre otras variables. Esto apoyó a que se concluyera sobre necesidades de estrategias de comunicación y diferenciación de sus productos o servicios una vez que conocieron la percepción de los consumidores. En algunos casos los resultados no fueron sorpresivos para algunas, en otros casos las participantes se encontraron con que las personas encuestadas no habían escuchado hablar del producto, otras tuvieron que reconsiderar su mercado meta, mientras que para algunas, el ejercicio les permitió conseguir nuevos clientes.

Las actividades tuvieron una combinación entre grupales e individuales, siendo las actividades grupales las de mayor aprovechamiento y practicidad dada la cantidad de participantes. Fue interesante observar la forma en que se organi- 
zaban para cumplir con las asignaciones grupales, varias de ellas se conocían con anterioridad, lo que facilitó enormemente que trabajaran en conjunto, además de que varias tenían proyectos de negocios en común. Algunas de las dinámicas grupales fueron enfocadas hacia el trabajo en equipo, en donde se reflexionaba los roles asumidos en cada una de las dinámicas.

Mediante estudios de casos se expuso un tema relacionado con una mujer emprendedora que no hallaba la forma de poner su negocio en marcha, debido a diversos temores que anteriormente se comentaron en esta investigación. A través del estudio de caso se logra escuchar diferentes opiniones y puntos de vista que permiten reflexionar sobre la iniciativa que debe imperar para la toma de decisiones.

El solo hecho de que las participantes estuvieran en el curso, ya era un indicio de su decisión de emprender un camino para superarse. Aun así, desarrollar una competencia como esta no basta con solo plantear estudios de casos que se resuelven en una sesión presencial, es necesario ponerla a prueba para observar su manifestación. Pero en algunos momentos surge sin provocarla, por ejemplo en algunas ocasiones se llevaron bocadillos para compartir, y fue gracias a la iniciativa de una o varias participantes.

Para evaluar cada competencia según el nivel con el que se expresa en cada una de las participantes se elaborara la tabla 4.

TABLA 4

\section{EJEMPLO DE EVALUACIÓN DE COMPETENCIAS}

\begin{tabular}{|c|c|c|c|}
\hline Competencia & Situación planteada & $\begin{array}{l}\text { Nivel de expresión } \\
\text { de la competencia }\end{array}$ & Observaciones \\
\hline \multirow[t]{4}{*}{$\begin{array}{l}\text { Iniciativa } \\
\text { Capacidad de tomar } \\
\text { decisiones alternas } \\
\text { ante situación adver- } \\
\text { sas o visionar sobre } \\
\text { las acciones que se } \\
\text { pueden tomar para } \\
\text { salir adelante con } \\
\text { una idea. }\end{array}$} & \multirow[t]{4}{*}{$\begin{array}{l}\text { Se le pide a los par- } \\
\text { ticipantes coordinar } \\
\text { la realización de una } \\
\text { feria de artesanías en } \\
\text { la expondrán sus pro- } \\
\text { ductos y servicios. }\end{array}$} & Sobresaliente & $\begin{array}{l}\text { Esta participante es la primera } \\
\text { en ofrecer un contacto para } \\
\text { poner globos inflables para } \\
\text { atraer al público en el lugar del } \\
\text { evento y rápidamente toma el } \\
\text { control con la distribución del } \\
\text { espacio, decoración de demás } \\
\text { requerimientos. }\end{array}$ \\
\hline & & Suficiente & $\begin{array}{l}\text { Esta participante ofrece, des- } \\
\text { pués de la anterior coordinar } \\
\text { el perifoneo y las cartas para } \\
\text { obtener los permisos. }\end{array}$ \\
\hline & & Moderado & $\begin{array}{l}\text { Esta participante ayudará a la } \\
\text { otra compañera a redactar la } \\
\text { carta y acompañarla. }\end{array}$ \\
\hline & & Deficiente & $\begin{array}{l}\text { Esta participante se limita a } \\
\text { observar las propuestas plan- } \\
\text { teadas y a seguir a las demás. }\end{array}$ \\
\hline
\end{tabular}

Fuente: elaboración propia. 
El ejemplo anterior fue parte de los proyectos finales que tuvieron que elaborar las participantes, la realización de una feria en la que ofrecieran sus productos, para ello se contó con el apoyo de la Oficina de la Mujer de la Municipalidad de Naranjo, quien facilitó el espacio del parque central de la comunidad. Como en toda coordinación existieron momentos de tensión, pero es en ese momento donde las competencias se expresan de forma más natural, y es ante ese tipo de situaciones en las que se puede evaluar mejor una competencia, observando comportamientos.

Evaluar una competencia supone en primera instancia definirla, delimitarla por niveles desde la que expresa la competencia en su grado más elevado hasta la que menos presencia tiene, puede ser delimitada con números 4,3, 2, 1, siendo 4 el nivel donde la competencia es sobresaliente y uno la de menor presencia, o pueden usarse palabras, símbolos, entre otros, lo importante es que el facilitador lo comprenda. Se debe plantear una situación que se pondrá a prueba para observar los comportamientos, relacionada con la definición planteada.

Si se detecta que uno de los participantes presenta deficiencia en alguna competencia se puede trabajar con ejercicios específicos para esa persona con el fin de que mejore.

Para la puesta en práctica de la competencia comunicación se manejó en conjunto con la negociación, se aplicó un ejercicio en el que después de exponer aspectos claves de una comunicación verbal y no verbal, se dramatizaron situaciones particulares en las que tenían que negociar su producto con un cliente y utilizando signos gestuales claves de aprobación, duda o desaprobación, entre otros.

La novedad fue sin duda el comportamiento que se enfatizó desde el primer día de sesiones. Durante las presentaciones grupales e individuales se enfatizó que las exposiciones que presen- taran tuvieran un componente novedoso. Una experiencia fue cuando tuvieron que presentar temas relacionados con aspectos financiero - contables, se les facilitó la idea de hacer dramatizaciones sobre situaciones reales en las que presentarán los temas planteados como costos, punto de equilibrio, entre otros. De esa forma se les instaba a pensar creativamente a la hora de pensar en sus propios productos.

Como apreciaciones finales, este artículo no pretendió detenerse en delimitaciones de espacio y tiempo para efectuar una capacitación, ni tampoco explicar sobre las diferentes técnicas de capacitación existentes, se concentró en mostrar al lector una experiencia de capacitación con ciertos matices que se involucran en cualquier tipo de entrenamiento, pero la motivación primordial se centró en mostrar una perspectiva hacia la exploración de las capacidades, destrezas y habilidades de las personas. El lector encontrará en ella una guía que podrá poner en práctica ante el planteamiento de cursos similares.

\section{CONCLUSIONES}

Esta investigación, guía para cursos basados en competencias para emprendedores, requerirá siempre como parte también de un proceso usual de capacitación la detección inicial de las necesidades y carencias reales del grupo antes de establecer las competencias a desarrollar.

Es una importante cantidad de información que debe ser absorbida en muy poco tiempo, por lo que duraciones muy cortas son contraproducentes. Debe darse un tiempo prudencial para que las personas interioricen los conceptos, procedimientos y pueda observarse un verdadero avance en la aplicación destacada de competencias. Tampoco se recomienda que la extensión del curso sea muy larga por tanto esto podría conllevar a una eventual pérdida de interés por parte de los estudiantes, además de qué 
está estrechamente ligado con las capacidades económicas que se disponga para abarcar un curso de largo duración.

Los modelos y la aplicación de la técnica por competencia generalmente se enfocan en el sector de las grandes empresas que cuentan con suficientes recursos para incorporar los principios de la técnica en sus empresas, pero también se pueden tomar recursos de la herramienta para aplicarla en capacitación en cursos de emprendimiento. Tal es uso de la técnica de selección por competencias para realizar el diagnóstico de la situación actual del negocio.

La práctica y el autodesarrollo se constituyen en los pilares para la exploración real de las competencias y determinar su fortaleza o debilidad mediante la observación. El facilitador deberá propiciar los espacios para su desarrollo usando como herramienta la evaluación de cada uno de los participantes para determinar sus áreas de mejora.

\section{REFERENCIAS}

Alcaraz, R. (2001). El emprendedor de éxito. (4ºd.). México: McGraw-Hill Interamericana.

Alles, M. (2010). Elija al mejor. Cómo entrevistar por competencias ( $2^{\circ}$ ed.) Buenos Aires: Granica.

Alles, M. (2010). Codesarrollo: Una nueva forma de aprendizaje. Buenos Aires: Ediciones Granica S.A.

Alles, M. (2008). Diccionario de comportamientos: Gestión por competencias. Buenos Aires: Ediciones Granica S.A.

Alles, M. (2007). Gestión por competencias: El diccionario. (2 ed.).Buenos Aires: Ediciones Granica S.A.

Fritzen, S. (1984). 70 ejercicios prácticos de dinámica de grupo. (6 ed.). España: Salterrae.

González, D. (2007). Plan de negocios para emprendedores al éxito. México: McGraw-Hill Interamericana.

Jiménez, D. (2007). Manual de Recursos Humanos. ( $2^{\circ}$ ed.) España: ESIC.
Hernández, R. Fernández, C., Baptista, P. (2003). Metodología de la Investigación. (3ed.). México D.F.: McGrawHill Interamericana.

McClelland, D. (1973). "Testing for competence rather than for "intelligence". American Psychologist, 28, 1-14.

Mussons, J. (1999). La empresa y la competitividad. España. Ediciones UPS S.L

Oficina Internacional de Trabajo (2009) Impactos de la crisis mundial en el mercado laboral de Centroamérica y República Dominicana. (Setiembre, 2009) Recuperado de http://portal.oit.or.cr/ dmdocuments/ impactos crisis mercado laboral may2009.pdf

Poveda, J., Parada, M., Vega, G., Araya, Z., Acuña, M., Arguedas, C., Ferreto, E., Vidas, L. y Cheng, L., (2009) Antología sobre capacitación en planes de negocios.

Recibido: 02 de julio de 2013 Aceptado: 30 de noviembre de 2013 